\title{
Precision and Systematization: On the Employment Guidance Service of Graduates from the Perspective of Connotation Construction in Colleges and Universities
}

\author{
Dandan Tong1 , Xiaoying Ma², Pengyu Guan ${ }^{1}$, ZhongWei Kang ${ }^{3 *}$ \\ ${ }^{1}$ College of Animal Science and Veterinary Medicine, Heilongjiang Bayi Agricultural University, 5 \\ xinfeng road, Daqing, China. \\ ${ }^{2}$ College of science, Heilongjiang Bayi Agricultural University, 5 Xinfeng road, Daqing, China. \\ ${ }^{3}$ General Administration Office, Heilongjiang Bayi Agricultural University, 5 Xinfeng road, Daqing, \\ China.
}

Keywords: Connotation of colleges and universities, Graduates, Career guidance service, Accurate

Abstract: The main contradiction of the society is changing, the new era calls for high-quality development, and the connotation construction of universities is becoming more and more important. The key point lies in "quality improvement". To realize the leap from "quantity" to "quality" of employment service work, it is necessary to actively change the concept, explore new ways, and expand the service function. From the marxism about the human essence theory and need theory, to respect the principal position of students in education, based on students, social relations and demand systematic construction of "four dimensions of eight framework" employment system, on the basis of graduation to differentiate between joint training, enter oneself for an examination the graduate student, enter oneself for an examination office jobs, entrepreneurship, employment in five modules, from students' characteristics, the guidance services strategy two dimensions make accurate working mode.

\section{Introduction}

The connotation construction of colleges and universities means that colleges and universities should make full use of the conditions and resources of running schools, constantly optimize the idea of running schools, pay attention to the development of the internal quality of schools, strive to improve the teaching standard, build a team of teachers with excellent style, and realize the sustainable development of the school [1]. Employment is the biggest project of people's livelihood, people's heart and foundation, and an important guarantee of social stability. The employment 
problem of college students is the result of the comprehensive effects of various factors such as society, economy, education system and individual factors [2]. Nowadays, the main contradiction of the society has changed. The key point of the connotation construction of colleges and universities lies in the "quality improvement", which puts forward higher requirements for the employment service. The leap from "quantity" to "quality" requires us to actively change our ideas, explore new ways and expand the function of employment service. Sticking to the writer's institution "improve the level of employment services, improve comprehensive competitiveness of graduates, and comprehensively promote high quality graduates employment work" for the purpose, follow the rules of a new era of college students growth, outstanding ", consciousness, service innovation, and feelings, normal and accurate "keyword, build modular accurate graduate employment guidance service system, strengthen the graduates" thoroughly, whole-staff-participation, informationization, specialization "guidance and services.

\section{Build a Systematic Employment Model to Ensure the Effective Employment Guidance for Graduates}

Colleges and universities, as the practice position of cultivating people with morality, are full of the characteristics of "the camp of iron fighting and the soldier of flowing water". In order to improve the quality of talent training, it is necessary to strengthen the "camp". In the writer's institution "around the focus of employment, deepen the connotation construction, ensure daily work efficiently finished, highlight the characteristics of innovation content and encourage participation and employment, and throughout the whole process of university education, help students quality promotion, service students grow up, constantly improve the quality of employment, to satisfied every graduate obtain employment" the general idea, build "four dimensions of eight framework" employment work operation mode, eight frame work of the communist party of China set up 28 secondary indicators. Figure 1 shows the employment management and service system.

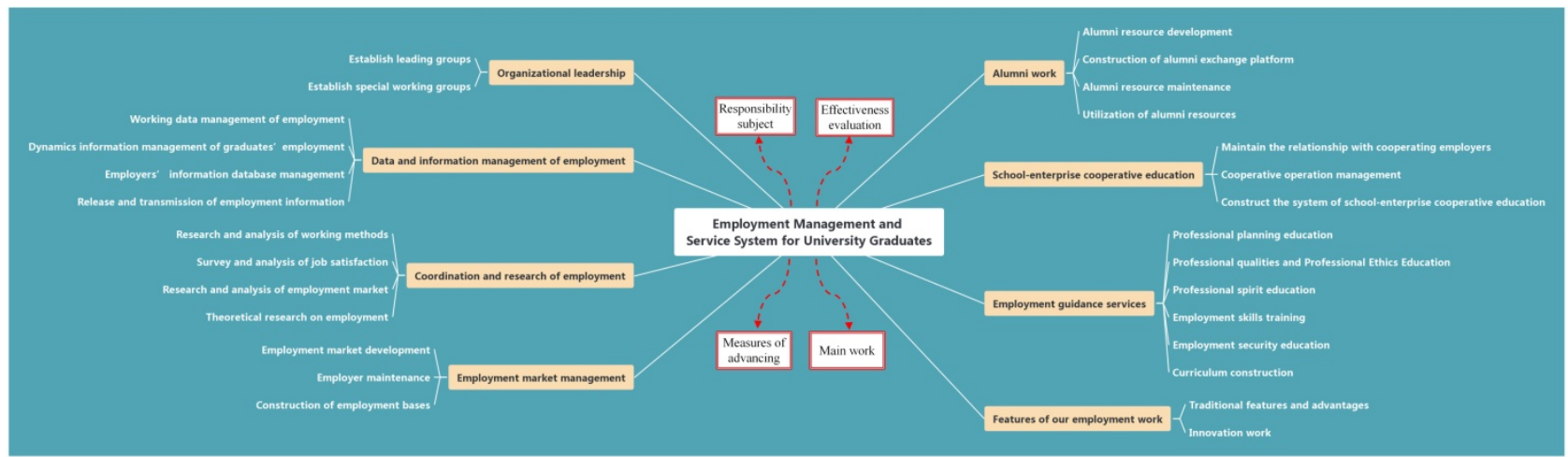

Figure 1 Employment Management and Service System for University Graduates

\section{Respect the Main Position of Students and Create a Precise Employment Guidance Service Mode for Graduates}

According to the Marxist theory of human nature and human needs [3], Employment work is a systematic project, and employment guidance service is the "core project" of this systematic project, 
which needs to run through the whole process of college life, and even extend to the period before and after graduation. For graduate groups, has come to seek a way out in the final stages of graduation, individual during the course of four years of college life choose characteristic to shape the "self", their personality, interests, values and ability are relatively mature, also have basic clear to graduation, to conduct a preliminary "people post match", then the group of employment guidance service point is "accurate", "private custom" service concept can be applied to the employment work, meet the reasonable requirements of students, sublimation students need high level. For graduation to index, on the basis of voluntary will graduate group is divided into university-enterprise joint training, enter oneself for an examination the graduate student, enter oneself for an examination office positions, entrepreneurship, five modules, including direct employment, employment guidance service strategy in the different modules design, build a system of precise work, formed "to the employment work operation system for the transverse, longitudinal axis for graduation to modular, implement the accurate employment guidance service" work pattern.

\subsection{Pay Attention to Standardization, Grasp the Main Line, and Improve the Employment Quality of Students in the School Enterprise Joint Training Module}

Under the popular education system, colleges and universities have formed diversified talent cultivation modes. "3+1", "2+2", order-type, school-enterprise joint training class and other commonly used school-enterprise joint training modes meet the needs of application-oriented talents cultivation. On the basis of scientific design of talent training plan for such student groups, in line with the responsibility for students, schools and enterprises, to achieve a good situation of "tripartite win-win", to achieve the "three norms" : first, standardize the school-enterprise joint training mechanism from the cooperation level. The cooperation mode and operation mechanism are constructed from multi-dimensional aspects such as target, task, process, organizational structure and cooperation mechanism to ensure smooth and efficient promotion of cooperation. Second, standardize the selection mechanism from the enterprise level. We will formulate sound selection criteria and procedures, implement the annual cooperation elimination mechanism, and ban the cooperative units that fail to keep up with the development, update the training content slowly and have low student satisfaction every year, so as to provide high-quality cooperative enterprises for the students. Third, standardize the selection mechanism of students. Under the premise of students' voluntary participation, students' individual characteristics, career pursuit, ability and expertise, etc. should be selected according to the principle of "the right person on", which is another key point for the joint training of schools and enterprises. The characteristic of choosing a job that school and enterprise unite to cultivate a student: it is to have clear seek a job volunteer. The target industry, the type of target enterprise and the target position of the students are relatively clear. Second, there is a high success rate of employment. Stable job-hunting mentality, clear job-hunting intention, strong job-hunting action, formed the advantages of early employment, quick employment; Third, there is a high risk of employment stability. Under the circumstance that students' career concepts and workplace cognition are not mature enough, the internship period of 
enterprises they choose for the first time is relatively long, and the probability of cognitive deviation or unreasonable emotions is relatively large. Moreover, most students think that they have rich practical experience in their self-evaluation, which affects the stability of employment.

For this kind of group of employment guidance services to grasp three main lines: one is to pay attention to the cultivation of professional thinking. Make "professional thinking" become "hot search word" in work and activities, guide students from the perspective of how to become a qualified professional, and improve students' cognition of accelerating role transformation; Second, pay attention to cultivate the bottom line thinking and awareness of trouble. Contemporary college students have a strong sense, compressive ability, and lack of self-control thought characteristic, under the background of management system and management ability of modern, more need to stick to the bottom line for young students thinking, increase the risk of consciousness, lead the students to learn on the job in adversity growth point of view, let the students more rationally think about his career life; Third, pay attention to cultivate students' understanding of the workplace environment. Knowing oneself and knowing the enemy, "the enemy" in job hunting is the workplace, in the macro situation and policy, the middle view of the industry and development and micro position and requirements of a comprehensive understanding of the workplace, from how to do their own job positioning perspective to lead students, to improve the "job matching" ability of students.

\subsection{Pay Attention to Help, Pay Attention to Detail, and Help the Postgraduate Module Students to Further Study}

In today's world, rapid development of science and technology, great changes in industry structure, increasing demand for high-level talents, and family life, economic pressure lowering, students for further study of intention, rise only this, one’s deceased father grind, similarly "army" continues to grow, but in addition to the affected by COVID - 19 outbreak in 2020 adopted the policy of enrollment expansion, the student enrollment no increased significantly in recent years, the supply and demand unbalanced pressure makes the students to further their studies. Choose to enter oneself for an examination graduate student's characteristic: it is the goal is opposite and clear. A small number of students will waver after applying for the exam. Some students are uncertain about the choice of colleges and majors. Although it is a small proportion, it has an impact on the stability of the group's goals. Second, psychological pressure is greater. High intensity of study, monotonous life, high expectations for success, etc., cause students preparing for the exam to produce greater psychological pressure, prone to emotional fluctuations, anxiety, or even depression; Third is the need for learning support systems. Some students choose to apply for cross-school, interdisciplinary and cross-major courses, and the depth of learning of specialized courses is larger than the daily teaching content, while the English foundation of some students preparing for exams in two or three colleges is obviously insufficient, so students need in-depth academic guidance.

Employment guidance service to lay the foundation for this kind of group, aim details: one is fixed number of year of the university system for life cycle take guidance services planning, according to the characteristics of the different grade students implement continuous line of thought 
led and the way of combining with policy support to develop one's deceased father grind guide service work, prison thought foundation, academic foundation; The second is to provide exquisite service. Policy and conditions allow, for students to "green light, send warmth", such as providing a special learning place, reduce unnecessary student activities, tell good stories, send enough spiritual strength; Third, we will implement detailed assistance and guidance during the critical period of preparation for war. From studies, psychology, economy, environment, second interview, and adjust strategies such as multidimensional create priority service for prepare for student groups, such as organization established between teachers and students, alumni one's deceased father grind school advisory group, policy advisory group, the psychological advisory group, etc., to carry out the academic support program, the school's association with plans, psychological counselling , policy advisory planning, etc., establish goals to enter oneself for an examination principle for one's deceased father grind struggle, achieve the goal of resource sharing, mutual encouragement.

\subsection{Pay Attention to Guidance, Grasp the Implementation, Enhance the Direct Employment Moudle Students Job-hunting Competitiveness}

"New industry, new technologies, new forms and new model" of the rapid development of the new situation, increased the contradiction between supply and demand of talent market, the "employment" and "labor shortage" of the situation, "Internet +" used in employment, change students' attitude, idea and way of activity, good jobs competitiveness is also on the rise, students' employment competitiveness is the key. The characteristics of the students in the direct employment module are as follows: first, there are two levels of individual job-seeking enthusiasm, professional ability and professional quality. Generally speaking, students with relatively high vocational ability and professional accomplishment have a higher sense of self-efficacy and more enthusiasm for job hunting. However, students with relatively insufficient vocational ability have a stronger possibility to avoid job-hunting activities, which affects their sense of self-efficacy. Overestimate or low self-efficacy will affect the job positioning and motivation; Second, the diversification of employment demand. This part of the student body the internal and external requirements for jobs are more, look from the inner ability and quality is uneven, there are differences between the personality traits and values demand, look from the outer region, a unit of the target of a job, post, such as the nature of work and treatment requirements are different, and family environment and family attitude to job objectives and action also has a great influence; Third, job expectations are generally high. The excellent growing environment and the lack of understanding of the job market and occupation make the students have higher requirements on many aspects of the occupational environment, especially the region, working environment, treatment and development space, etc. The contradiction between the pursuit of "good job" and their own lack of ability is more prominent, and the difficulty of guiding the grassroots employment increases.

The employment guidance service for this group should balance the guidance and service, give consideration to the general and the special, and implement diversified measures. On the positive side, the "non-employment" group is very few, and the slow employment and lazy employment of students is an important resistance to the promotion of employment work, with a greater probability 
of transformation under the correct, timely and effective guidance. By applying Lenin's "indoctrination theory", the diversified approaches of information dissemination, policy publicity, forum discussion, expert report, model display, data announcement and so on are integrated to deliver positive information to students on a regular basis, so as to form a ubiquitous atmosphere of "influence". Combine the employment work with the ideological and political education work, arm the students with the marxist theory and its Chinese achievements, and guide the students to understand the employment from the social and national development status and trend. Second, further classification and classification, to develop students' career planning personalized guidance. Personalized guidance of career planning emphasizes the combination with the reality of school's characteristic positioning, and the combination of career planning with the actual needs of society and enterprises [4]. In the case of diversified employment needs of graduates, it is necessary to classify them again and develop "personalized" guidance in order to ensure the effectiveness of information received by the recipients, namely students. According to the current situation of job-hunting, students are divided into stable employment, active employment, re-examination of graduate school, employment difficulties and other categories. Dynamic management is implemented, and employment difficulties are graded according to the degree of classification. Third, the guidance service is in place. Aiming at the group of prospective graduates, due to limited time and energy, with the goal of improving students' job-hunting competitiveness and employment stability, and with the demand side of students and enterprises as the foothold, we provide guidance services of "checking gaps and making up for gaps". To carry out the education and employment "strategy, to carry out the job preparation workshop, professional quality, lecture hall, employment career combat battalion, interviews and other activities, promote employment ability promotion planning, alumni mentoring program, making graduates job treks content such as manual, employment resource database, and try to make up the spirit of the employment" ca ", the source of power.

\subsection{Pay More Attention to Planning, Grasp Accurate Degree, Safeguard Enter Oneself for an Examination Public Service Kind Post Module Student to Have Outlet}

The factors such as the relatively stable income of the enterprise staff, the relatively good welfare policy and the relatively good security after retirement are attractive to students and their parents. With the standardization and transparency of the recruitment of talents in public institutions, it provides students with a more fair opportunity to compete. Choose to enter oneself for an examination of the characteristics of the students of public service position: first, the mentality of "slow employment" is stronger. I have relatively high requirements on working environment and working salary, and I hope to get a relatively stable and low-pressure job. If I fail the first exam, I am more inclined to continue to take all kinds of exams. Second, the planning ability of job hunting needs to be strengthened. Some students choose the path of taking public office due to their lack of self-assessment and environmental awareness. Third, the urgent psychology of asking for help. There is a gap between the content of public examinations and that of university study, especially in 
the interview process, which requires more comprehensive quality. Most students who prepare for the exam feel that this field is relatively unfamiliar and need more guidance and help.

The employment guidance service for this group should pay attention to the guidance of accurate positioning and scientific planning. To guide students to conduct in-depth self-analysis and career understanding by applying career planning concepts and theories, and to guide them to design suitable job objectives; Second, "one person, one strategy" personalized service. The success rate of taking the public office is low, and the "two-point theory" and "key point theory" are used to actively lead students to set the dual goals of taking the public office and seeking a job. With the help of teachers with examiner experience, double teachers, alumni and other groups in the examination and interview to give full group or individual guidance, counselors in the job search for "one-to-one" guidance services; Third, continue to follow up at any time guidance. To track and guide students' status, guide and adjust the "key points" in the target, and improve the "slow employment" status.

\subsection{Focus on Practice, Grasp the Cultivation, and Strive to Achieve the Dreams of Students of the Self-employment Module}

Innovation is the primary driving force for development, and mass entrepreneurship and innovation are regarded as one of the "two engines" of economic development under the new normal. The national and local governments have given college students various advantages in starting their own businesses. At present, more and more college students choose entrepreneurship as their employment form upon graduation, which reflects the autonomy and independence of contemporary college students [5]. The characteristics of students who choose to start their own businesses: first, they have certain entrepreneurial aspirations and experience. Generally speaking, these students have their own or family entrepreneurship experience, or have hosted or participated in innovation and entrepreneurship activities, and have a relatively clear desire for entrepreneurship; Second, overestimate the value of their own entrepreneurial experience and ability more phenomenon. Compared with other students, they are more active in thinking, more independent, have "different" experience and experience, and have an increased sense of superiority. Third, the will of multi-path career is not strong. They have a strong ability to accept and explore new things, and have a certain motivation to act. After determining the goal of "entrepreneurship", they are willing to take actions and expect results, and are unwilling to allocate time and energy to seek other careers.

The employment guidance service aimed at this kind of group should gather resources and combine efforts: first, guide the in-depth self-analysis. Using the knowledge of career planning to teach students to carry out in-depth SWOT analysis and formulate entrepreneurial action strategies that can "play to strengths, make up for weaknesses, seize opportunities and avoid risks". If the conditions for starting a business are not mature, timely guide the target "transformation"; Second, multi-party assistance to provide comprehensive guidance on entrepreneurship. From the double perspective of improving ability and cultivating projects, we invite industrial and commercial organizations, tax authorities, financial institutions, investment companies, law firms and other institutions to provide guidance and provide professional entrepreneurial consulting services for 
students with the help of social resources. Through the city school, school, school jointly create entrepreneurial practice alliance, to provide students with practical training opportunities; Third, pay attention to psychological debugging and counseling. Entrepreneurship students have relatively many pressure sources, but their own experience, capital and literacy are far from the actual needs. They need to pay attention to students' mental health status at any time, disseminate mental health knowledge, and improve their ability to bear pressure, relieve emotions and relieve pressure.

\section{Conclusion}

Employment is the foundation of people's livelihood and a major event related to social harmony and stability. The main responsibility of colleges and universities is to cultivate talents for social development. Employment is closely related to the export of these students, which has attracted the attention of most families, colleges and universities, and the whole society. Nowadays, the reconstruction of lifestyle and work patterns by information technology makes the industrial structure change substantially, with new forms of business emerging one after another and the situation of industrial development changing uncertainly, which accounts for the reason why students' thinking and attitudes are diversified. Colleges and universities need to guide students in time and precisely, promoting students' cognitive abilities toward employment to meet the demands of the times. That is to say we have to construct the module according to the indexes of students' destinations after graduating, analyze the job-seeking features of graduates in each module and design guidance service strategies respectively, forming a set of modular and precise employment guidance service system. This system will be of great realistic and guiding value for colleges and universities to implement the strategy of cultivating students in accordance to their aptitude with the tendency of the situation, as well as other social organizations to carry out similar work.

\section{References}

[1] Yu L., Quande L. The connotation construction path of "college" upgraded to "university". Journal of higher education, 2019 (23): 194-196

[2] Yali L. Value analysis of career planning in college students' employment guidance work. Chinese and foreign entrepreneurs, 2020 (11):159

[3] Marx, Engels. Selected works of Marx and Engels (vol. 1). Beijing: people's publishing house, 1995

[4] Yanmin P. Reflections on college students' personalized guidance based on career planning. Think tank times, 2020 (06): 117-118

[5] Yaotian W., Zhiyue L.A study on the integration of college ideological and political education and career guidance education. College education, 2020 (03):124-126 